\title{
A presença de elementos míticos na filosofia de Empédocles
}

\author{
Mythic elements in empedocle's philosophy
}

\author{
Nayra Sousa Barros ${ }^{1}$ \\ Rafael César Pitt²
}

\author{
1 Acadêmica do Curso de Filosofia da Unifap - Campus Santana, Brasil. \\ E-mail: nayraww@gmail.com Orcid: http://orcid.org/0000-0002-1794-4054 \\ 2 Professor do Curso de Filosofia da Universidade Federal do Amapá, Brasil. \\ E-mail: rafaelpittunifap@gmail.com Orcid: http://orcid.org/0000-0003-4045-6574
}

RESUMO: O tema do presente artigo é a presença de elementos míticos na obra do pré-socrático Empédocles de Agrigento. O problema que nos dispomos a abordar é discutir a possibilidade de haver uma noção filosófica que tenha ao mesmo tempo significado mitológico e filosófico. Os objetivos foram num primeiro momento resgatar a figura do aedo a fim de mostrar a persistência de formas poéticas antigas na nascente filosofia. Em seguida, comparamos a teogonia de Hesíodo com a cosmologia empedocleana de forma a destacar a estrutura narrativa subjacente, isto é, o jogo de forças cósmicas personalizadas, assim como a concepção mítica da Idade de Ouro. E por fim discutimos os pontos de interseção entre práticas purificadoras presentes na poesia do agrigentino e preceitos religiosos derivados da tradição órfica. Nossa metodologia foi essencialmente bibliográfica ao apresentar vários estudiosos sobre os temas escolhidos. Nossos resultados indicam que a noção de daimon perpassa as três fontes referidas (Hesíodo, Empédocles e orfismo), de modo que sua abrangência elástica dialoga tanto com o mito quanto com a filosofia e a poesia. Concluímos que Empédocles inspirou-se nas antigas poesias hesiódicas e práticas órficas para realização e formação do seu pensamento apresentando, pois, alguns elementos míticos em sua filosofia.

Palavras-Chave: Empédocles; Mito; Filosofia.

ABSTRACT: The theme of this article is the intertwining of mythical elements in the work of the pre-Socratic Empedocles of Agrigento. The problem we are willing to address is to discuss the possibility of a philosophical notion that has both mythological and philosophical significance. The objectives were at first to rescue the figure of the aedo in order to show the persistence of ancient poetic forms in the early philosophy. We then compare Hesiod's theogony with Empedoclean cosmology in order to highlight the underlying narrative structure, that is, the play of personalized cosmic forces, as well as the mythical conception of the Golden Age. Finally, we discuss the intersection points between purifying practices present in agrigentine poetry and religious precepts derived from the orphic tradition. Our methodology was essentially bibliographic in presenting several scholars on the chosen themes. Our results indicate that the notion of daimon runs through the three sources mentioned (Hesiod, Empedocles, and Orphism), so that its elastic scope dialogues with both myth and philosophy and poetry. We conclude that Empedocles was inspired by the old hesiodic poetry and orphic practices for the realization and formation of his thought presenting, therefore, some mythical elements in his philosophy.

Keywords: Empedocles; Myth; Philosophy.

\section{Introdução}

Este estudo visa trabalhar os aspectos míticos no pensamento de Empédocles (1996), pelo menos 
aqueles identificados por influência hesiódica ou órfica. De Hesíodo (1995), por exemplo, temos a Idade de Ouro aonde homens e deuses conviviam harmoniosamente sem qualquer distinção. Assim como, da parte da antiga tradição órfica, uma série de indicações que expurgam o mal da alma a fim de libertá-la do ciclo de reencarnações. Estes pontos se sobressaem em nossa análise quando abordamos o conceito de daimon ( $\delta$ i $\mu \mathrm{ov})$ em Empédocles e no orfismo de modo a destacar suas confluências.

Também veremos o conceito ou ideia de Esfero para Empédocles para o qual seria o princípio originário onde os quatros elementos se reuniam por força de Amor (Eros), antes da presença de Ódio (Neikos). Enquanto participante do processo criador deste princípio esférico, porém dividido em corpo e alma e dentro do cosmos pluralizado pela complexa rede de mistura dos quatro elementos iniciais, ao homem é dada a oportunidade de retornar à unidade originária do Esfero mediante sua purificação. É nessa perspectiva que falaremos sobre o daimon em Empédocles, elemento responsável por conduzir o homem para o puro ou para o impuro, para sua parte divina ou sua parte mortal. Isso é possível a partir das práticas e receituário órfico contido nos versos de "Purificações".

Da mesma forma que relativo ao contexto do orfismo, o daimon empedocleano faz uso da poesia de Hesíodo para mostrar que, antes da inserção de Neikos no interior de Esfero, o homem desfrutou de determinada condição divina de existência cósmica. Foi assim que, no tempo imemorial do mito, o homem teria vivido na Idade de Ouro, isto é, aquele período de convivência pacífica e frutífera entre homens e deuses. Isto nos mostra como, para o filósofo pré-socrático, é possível falar de uma queda quando o daimon teria experimentado uma espécie de crime ou falha e se sujeitado aos ditames inferiores da encarnação e da mistura dos elementos. Para usufruir de paz e plenitude novamente faz-se obrigatória, portanto, uma vida de retidão, de renúncias e ações controladas visando a elevação da parte divina de cada um.

\section{A tradição do aedo...}

Por muito tempo o conhecimento, a história e cultura dos gregos antigos eram retratados pelos mitos sobre a origem e a ordem do universo. Sobre a importância do mito para os gregos, salienta Jean Pierre Vernant que "essas narrativas, esses mythoi, tanto mais familiares quanto foram escutados ao mesmo tempo em que se aprendia a falar, contribuem para moldar o quadro mental em que os gregos são muito naturalmente levados a imaginar o divino, a situá-lo, a pensá-lo” (2006, p.15). É na referência cultural aos mitos que os primeiros pensadores compuseram suas teorias sobre a origem do universo e do homem, assim como fundamentaram suas teses sobre a substância primordial (arkhể) de onde sucederam os demais seres que existem.

A questão então se desloca para o como estes mitos passavam através das gerações dos antigos gregos, o que nos leva até os poemas e cantos dos poetas.

Toda a visão de mundo e consciência de sua própria história (sagrada e/ou exemplar)... conservada e transmitida pelo canto do poeta. É através da audição deste canto que o homem comum podia romper os restritos limites de suas possibilidades físicas de movimento e visão, transcender suas fronteiras geográficas e temporais, que de outro modo permaneceriam infranqueáveis, e entrar em contato e contemplar figuras, fatos e mundos que pelo poder do canto se tornam audíveis, visíveis e presentes. $\mathrm{O}$ poeta, portanto, tem na palavra cantada o poder de ultrapassar e superar todos os bloqueios e distâncias espaciais e temporais, um poder que só lhe é conferido pela Memória (Mnemosyne) através das palavras cantadas (Musas). (TORRANO, 1995, p.11). 
Até então, o homem grego só conhecia sua história, sabia de seus antepassados através das poesias

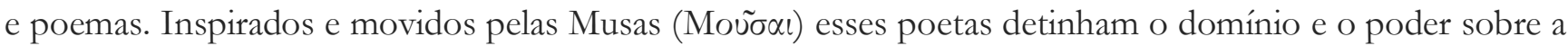
palavra, sobre o conhecer e principalmente o saber mitológico. O povo grego escutava as poesias cantadas a fim de conhecer mais sobre seu próprio passado e de como ele veio a ser tal como é no presente. Deste modo, os aedos eram transmissores de um conhecimento divino e, como tais, repassavam adiante aquilo que tinha sido originalmente de poder exclusivo dos deuses.

\section{... De Hesíodo até Empédocles}

Entre os poetas gregos, Homero e Hesíodo obtiveram grande influência na construção da narrativa dos mitos, assim como na construção do pensamento racional do homem grego. O segundo compôs duas obras "Os Trabalhos e Os Dias" (2012) e a "Teogonia”. A última nos conta como o mundo surgiu a partir dos primeiros deuses, seus amores e suas lutas. Ela constituía, com os poemas de Homero, a cartilha na qual os gregos aprendiam a ler, a pensar, a entender o mundo e a reverenciar o poder dos deuses. De certa forma, a "Teogonia" é o mais antigo relato de mitologia grega que chegou até nós.

Especialmente os poemas teogônicos de Hesíodo serviram como pano de fundo para os présocráticos que, direta ou indiretamente, replicaram a genealogia divina, os poderes cósmicos e o escopo simbólico da cosmologia ali contida. Noções importantes como arkhé, kósmos, lógos e physis tiveram suas raízes no texto de Hesíodo e, por isso, o entrelaçamento entre a filosofia e a mitologia foi e, de certa forma, ainda é, um tema tão discutido. Já na antiguidade Aristóteles reconhecia a irmandade entre os campos. “Aquele que ama o mito é, de certa forma, filósofo" (2001, p. 18).

Empédocles de Agrigento mantém a regra de continuidade da tradição poética antiga. Segundo Jean Brun (1991) a influência do mito é nítida, por exemplo, no tema da antiga união plena entre homens e deuses. Cito: "Empédocles fala de um paraíso perdido e de uma idade de ouro primitiva onde reinava a inocência. De lá os homens foram precipitados sobre a Terra, onde estão sujeitos à luta dos contrários” (p. 75). Somente através das purificações eles conhecerão de novo a época em que "todas as criaturas eram familiares e doces para com os homens, tanto os animais selvagens como as aves" (EMPÉDOCLES, 1996, p. 209).

\section{0 orfismo}

Como crença e culto não oficial do estado, o orfismo tem como principal referência o mito de Orfeu. Este é bastante complexo e envolve pelo menos quatro subpartes: a aventura compartilhada com Jasão em busca do velocino de ouro quando Orfeu se destaca dentre a tripulação como vate e excelente músico - destaque para a vitória sobre o canto das sereias; a paixão idílica pela jovem Eurídice interrompida pela morte abrupta da jovem; a descida ao Hades para resgate da alma da amada e consequente perda definitiva da mesma; e por fim a triste figura solitária cabalmente esquartejada pelas mulheres da Trácia. O orfismo como tradição de mistérios se concentra sobre a terceira parte quando, ao retornar do mundo dos mortos, Orfeu teria trago uma série de conhecimentos e preceitos úteis para os dedicados à vida após a morte.

Característica importante na religião órfica é que "elas se opõem diametralmente à tradição hesiódica” (VERNANT, 2006, p.82). Diferente da cosmogonia hesiódica, na órfica as origens dos seres estavam 
presentes através do Ovo Primordial, representante da unidade perfeita, a plenitude de uma totalidade fechada. "Aos poucos ele corrompe e degrada-se a unidade perfeita, fazendo surgir os demais seres ou indivíduos. A esse ciclo de dispersão da parte do Ovo sucede um ciclo de reintegração das partes na unidade do Ovo." (OLIVEIRA, 2004, p.21).

Na mitologia órfica, Dioniso Zagreu foi filho de Zeus e Hera, porém odiado pelos Titãs devido a seu destino de herdar o trono do pai. Os Titãs acabam matando Zagreu, o que provoca a fúria de Zeus que os fulmina com o raio. Desta cena horrenda parte do sangue de Dioniso se mistura com o pó restante dos Titãs. Desta mistura de algo puro com uma parte impura, de algo elevado com algo caído, surge a raça humana. Logo, os homens são "marcados por um lado divino e espiritual ou dionisíaco; outro de origem titânica, material e corporal” (OLIVEIRA, 2004, p. 10). O mito dionisíaco representa a dualidade do sagrado e do profano para os órficos, daí a relevância de se observar e praticar os saberes secretos que Orfeu trouxe do além-vida.

Purificando-se da falta ancestral pelos ritos e pelo tipo de vida órficos, abstendo-se de toda carne para evitar a impureza desse sacrifício cruento que a cidade santifica..., cada homem, tendo guardado em si uma parcela de Dioniso, pode, também, retomar à unidade (VERNANT, 2006, p.83).

Os órficos praticavam o vegetarianismo, eram contra o derramamento de sangue de animais e evitavam o contato com corpos mortos, vestindo-se sempre de branco. Eles acreditavam que o corpo é a prisão da alma, pois esta deseja juntar-se à sua parte divina dionisíaca. Para conseguir esse fim, era necessária a iniciação e purificação órfica com o intuito de pagar todas as suas culpas devido a seu perfil titânico.

Mera coincidência que não tem como passar despercebido é o pré-socrático de Agrigento escrever uma obra cujo título é "Purificação". "A purificação era um procedimento ritualístico para libertar de um pecado por meio de uma série de práticas. Empédocles se apresenta, portanto, neste poema como portador de uma mensagem de purificação e salvação" (BERNABÉ, 2008, p. 20). Assim como entre os órficos que "através de regras rígidas de conduta, rituais de iniciação, regras de ascese, catarse e purificação, estudos e conselhos para o post mortem, buscava aparelhar o homem para o bem-viver e para o bem-morrer" (PIRES, 2006, p. 104) - o pré-socrático demonstra ser mais um aedo e transmitir um saber elevado. Fazendo uso de elementos míticos da teogonia hesiódica (como a idade de ouro) e do orfismo (a salvação da alma) - construiu sua filosofia sobre o embate das forças opostas do amor e do ódio sem perder de vista a possibilidade de retorno à unidade primordial do Esfero.

\section{Os quatros elementos}

Empédocles elevou o amor e o ódio humanos ao patamar divino com Eros e Neikos uma vez que são duas forças cósmicas responsáveis pela atração e repulsão entre os elementos primordiais. Para nosso filósofo, os opostos não se atraem, mas pelo contrário, o semelhante atrai o semelhante e o dessemelhante repulsa o dessemelhante. E esse movimento é considerado eterno, um ciclo constante no qual a harmonia prevalece quando Eros age, e vice versa, a desarmonia quebra o equilíbrio quando Neikos atua.

Segundo a cosmogonia de Empédocles todos os seres, inclusive o homem, são compostos pelas quatro raízes primordiais: fogo, terra, ar e água. "Mesmo o cosmo, uma vez tomado como um todo, encontra-se composto por elas, visto que cada ente que nele ocupa um determinado lugar vem a ser consoante uma composição específica entre esses quatro elementos” (COSTA, 2012, p. 112). 
No caso do homem há a abertura gerada pela parte divina que o compõe. Isto quer dizer que cabe a ele uma possibilidade singular dentre todos os seres criados, a saber, o conhecimento prévio da natureza dos quatro elementos, assim como das duas forças que agem sobre eles, pode lhe ser adequada a um fim superior. A ignorância ou, ainda mais precisamente, o não-saber a respeito disto, é o fator de afastamento do homem de sua depuração, impedindo-o de purificar a si mesmo. É necessário que ele saiba, por exemplo, que o consumo de certos grãos como o feijão, e principalmente de carne animal, o "prende" à sua parte terrena e lhe atrasa, se não mesmo, impede que o mesmo fortaleça sua parte imortal.

Os quatro elementos em si mesmos possuem idêntico valor metafísico. Significa que nenhum deles é superior ao outro ou possui maior ou menor aderência a uma das forças combatentes. Por um lado, isto mostra como o jogo entre o amor e o ódio não deve ser vistos como um embate moral entre o bem e o mal. Na verdade, nenhuma das forças é sujeita a julgamento ético. E por outro lado indica como Empédocles pensa os quatro elementos com uma visão que hoje chamaríamos de "científica". Interessa-lhe sobretudo o caráter físico dos elementos, suas intrínsecas capacidades organizativas e associativas que beiram o número ilimitado. De fato, o pré-socrático chega a oferecer alguns "cálculos" que indicam como ele pensava quase matematicamente o poder combinatório dos quatro elementos.

Mas a terra amorosa em amplos recipientes, duas partes das oito recebeu de Nestis brilhante, e quatro de Hefesto; e os ossos brancos nasceram, pelo cimento de Harmonia divinamente ajustados. ${ }^{1}$ (EMPÉDOCLES, 1996, p. 203).

Isto é, concretamente falando os ossos são compostos da combinação de $2 / 8$ de água com 2/4 de fogo e $2 / 8$ de terra.

\section{Esfero}

Tanto os elementos como as forças que atuam sobre eles são divinos. O deus é o Esfero, mas que podemos entender por Esfero em Empédocles? É como se fosse um núcleo, onde o mesmo reúne os quatros elementos sobre regência do Amor, "durante o qual não há geração de seres, mas apenas a unidade da multiplicidade, ou seja, o sphairos uno e igual a si mesmo" (PEREIRA, 2006, p. 127). A união de todos os elementos através do amor ou da amizade. $\mathrm{Na}$ fase em que o amor domina todos os elementos eles estarão ligados em perfeita harmonia. Nessa fase não existe o sol, a terra ou o mar, mas uma unidade de tudo que Empédocles denomina como sendo o Esfero. Ao contrário do domínio do amor, no domínio do ódio existe a dissolução dos elementos e forma-se assim o caos. Do caos começa o movimento de individuação dos seres e separação da unidade esférica.

Portanto as coisas do mundo passam a existir no período de transição que vai do predomínio do amor ao predomínio do ódio. Assim o cosmo nasce e se destrói continuamente dependente e através da ação das duas forças sobre os elementos. Não existe um momento em que a constituição do cosmos possa ser considerada finalizada.

\section{Daimon}

O filósofo explica que no homem habita um daimon oriundo do mundo dos deuses que foi conde-

1 Ou seja, de água. Hefesto é o fogo e Harmonia equivale à Amizade. 
nado a viver na terra em punição de uma falta cometida, a qual expiará somente no curso de reencarnações sucessivas. Por se tratar de um ser divino, desterrado do convívio dos deuses, buscará escapar o mais rápido possível do círculo das encarnações dentro do mundo da Discórdia (Neikos) para recuperar seu lugar junto aos deuses de longa vida. "Quando o daimon tem consciência de sua origem e destino divinos, como é o caso de Empédocles, ele buscará purificar-se através de práticas que o ajudem a se libertar da escravidão do corpo" (DELATTE apud PEREIRA, 2003, p. 108).

Indistintamente operam amor e ódio no homem, mas cabe àquele que sabe e - porque sabe - resolver-se por essa ou aquela atitude diante desse antagonismo entre os princípios. Trata-se de possibilidade ao alcance do homem e é por ela que Empédocles se decide, assim como é por intermédio de sua filosofia que estende sua decisão aos demais homens, conclamando-os às suas purificações. "Aqui assume a filosofia de Empédocles a forma e o valor de uma sabedoria não exatamente de vida, mas para a vida, no sentido de comprometer-se com aquilo que a favorece” (COSTA, 2012, p. 106).

Assim como só o amor é divino na cosmologia empedocleana, o "lado" do ódio parece corresponder à força que no homem o condena a não ser um deus. "Confirma-se assim uma vez mais que o seu retorno ao divino requer todo o seu empenho em prol do amor, movimento este que quanto mais se intensifica mais o desumaniza ou, dito de outra forma, mais o diviniza" (COSTA, 2012, p. 109). Empédocles, ao observar essas duas forças reinantes no homem assume as práticas órficas a fim de auxiliar aqueles que desejam a salvação ou maior aproximação de seu daimon com o divino.

\section{Daimon (em Hesíodo) e A Idade de Ouro}

O aspecto mítico em Empédocles acerca do daimon que focaremos trata deste termo em Hesíodo e sua influência no pensamento de Empédocles. Na tradição hesiódica os daimones são os homens da raça de ouro que originalmente viviam como deuses e que, com o fim deste período, foram convertidos por Zeus em mensageiros divinos encarregados de zelar pelos mortais. Conforme os seguintes versos de Os Trabalhos e os Dias:

Mas desde que a terra encobriu essa raça, eles são divindades pela vontade de Zeus grande, nobres, terrestres, guardiões dos humanos perecíveis;

\{eles vigiam as sentenças e as cruéis ações,

(125) vestidos de bruma, vagando por toda a terra, distribuidores de riquezas: obtiveram esse privilégio de reis. (HESÍODO, 2012, p. 75).

Quando o daimon possuir consciência de sua queda e falha, buscará purificar-se da sua escravidão carnal e libertar-se do ódio e discórdia que há dentro de si. "O ser divino exilado da companhia dos deuses, e que é forçado a se purificar através da transmigração. No homem, daimon é uma força interior ativa, que age para modelar sua vida" (DARCUS apud PEREIRA, 2006, p.185-186). Desejará ter uma vida de abstinência, por exemplo, da carne, do derramamento de sangue; com a finalidade do daimon encontrar sua parte divina ou retornar para aonde sempre pertenceu, a Idade de Ouro.

Em alguns versos de "Os Trabalhos e os Dias" Hesíodo fala de uma Idade de Ouro a qual os deuses e homens viviam e conviviam em plena harmonia, felicidade e paz. Os homens não conheciam o nascimento e tampouco, a morte. Naquela época não existia trabalho, nem doença e sofrimento. Toda manhã 
ao acordar o homem encontrava uma mesa a luz do sol, repleta de alimentos e bebidas. Uma vez ou outra, os deuses assentavam junto aos homens a mesa para banquetear ou festejarem juntos. Tudo que o homem precisava para seu bem viver, ele possuía, como podemos ver nos versos 109 a 119:

(109) Primeira de todas entre os humanos de fala articulada,d fizeram os imortais que têm moradas olímpias uma raça de ouro.

Eles existiram no tempo de Crono, quando este reinava no céu; como deuses viviam, o coração sem cuidados, sem contato com sofrimento e miséria. Em nada a débil velhice estava presente, mas, sempre iguais quanto aos pés e as mãos,

(115) alegravam-se em festins, fora de todos os males, e morriam como que vencidos pelo sono. Tudo que é bom possuíam: a terra fecunda produzia seu fruto espontaneamente, muito e de bom grado. Eles, voluntária e tranquilamente repartiam os trabalhos, tendo bens abundantes. (HESÍODO, 2012, p. 73).

São muito próximos, portanto, os versos hesiódicos acerca da Idade de Ouro com a concepção mítica do homem e do cosmo em Empédocles. Especialmente quando Hesíodo afirma a origem de uma era a qual todos os seres conviviam em mútua harmonia e amabilidade. Isso nos lembra no pensamento cosmogônico de Empédocles do seu Esfero a qual todos os quatros elementos estavam sob o comando do amor numa harmonia e paz eterna. O Esfero é anterior a qualquer ódio, qualquer divisão, é contra a luta e a multiplicidade. É referindo-se a esse Esfero que o pré-socrático nos lembra da Idade de Ouro hesiódica, que infelizmente essa idade teve um fim e os homens foram sujeitos a tamanho sofrimento, tristeza e trabalho para viverem. Podemos então concluir que o fato do ódio ter entrado em ação no Esfero separando os elementos para mudar o destino do homem é, igualmente, assemelhado à saída dos homens da idade de ouro em Hesíodo.

\section{Daimon no Orfismo}

Empédocles contempla a existência na Terra como algo fundamentalmente negativo, quase como uma lástima. Em seus versos fala-se, entre outras coisas, dos tortuosos caminhos da vida dos desafortunados e também do gênero miserável, infeliz e desgraçado dos mortais. O daimon em Empédocles estaria exilado dos deuses, vagando erroneamente, submetido a um conflito permanente entre amor e ódio. Necessita o daimon passar pelas práticas de purificações e por uma longa série de reencarnação para, em cada uma delas, "subir de categoria", isto é, se purificar mais e mais. É neste sentido que lemos a seguinte passagem do pré-socrático .

Já com efeito eu outrora fui menino, menina, arbusto, passarinho e, do mar saltando, mudo peixe. (EMPÉDOCLES, 1996, p. 208).

Como já mencionado anteriormente, o daimon empedocleano é influenciado por sua parte que contém o ódio assim como pelo amor. Cabe ao homem renunciar a seu lado da discórdia e alimentar o amor em suas encarnações, alimentando a parte divina que lhe compõe e que pertence ao mundo dos deuses. Da mesma forma, para os órficos o daimon é imortal e reencarnaria diversas vezes até purificar-se completa- 
mente das máculas e crimes praticados por seu quinhão titânico. Era necessário educar a alma para encerrar o ciclo de nascimentos e regressar ao divino, pois para eles o corpo seria a prisão da alma, cárcere expiatório das culpas.

O orfismo ordenava a prática de rituais que serviriam para a limpeza do corpo e a purificação da alma (do daimon). A crença básica era de que o homem, ao purificar a sua alma, retornaria à bem aventurança. Por isso, aos homens já iniciados não era permitido alimentar-se de carne, haja vista o simbolismo da morte já mencionada de Dioniso Zagreu. O sacrifício animal significava para os antigos em geral uma forma de entrar em contato com os deuses. Diferentemente, na visão órfica a comunicação com a divindade era possível pelo próprio homem através dos costumes. Assim, o homem se livraria de todas as impurezas que lhe impediam de ser puro. Nesse sentido, os rituais de holocausto faziam parte da tradição oficial, radicada no mito de Prometeu - para os órficos - prática desnecessária, afinal, todo homem possuía dentro de si uma parte divina.

As diferenças entre as duas correntes tornam-se claras no sentido das práticas rituais. No dionisismo, o ritual consiste em matar um animal estraçalhar-lhe e comer-lhe a carne crua. O fiel que se alimentou com a carne comunica-se com a divindade. O orfismo prega uma prática radicalmente oposta. Nele a comunicação com o deus é desnecessária, porque o carrega em si uma parte divina, ele é o Baco. A crença do homem ser o deus fica clara ao lermos em uma lamela "eimi Bakkoos", ou seja, "eu sou Baco". Essa diferença no significado da relação do homem com a divindade permanece presente e justifica toda a prática de ambos os movimentos. (OLIVEIRA, 2004, p. 12)

As abstinências recomendadas tinham a finalidade de fazer o daimon expulsar tudo de estranho e ruim que o corpo havia adquirido por intermédio das suas inclinações. Um instrumento importante utilizado nesse processo eram as liturgias, uma inovação do Orfismo, pois as outras religiões utilizavam o recurso da palavra falada, nos rituais. Nas cerimônias, os órficos acreditavam que desde que o iniciado soubesse ler, através do contato direto com esses escritos, sem a intermediação dos demais participantes, poderia ter um melhor aproveitamento dessas palavras milagrosas.

O cuidado que a tradição órfica e Empédocles tinham para com o daimon do homem pode ser explicado pela doutrina da imortalidade da alma. O homem passava pelo ciclo de reencarnações onde a alma tinha a oportunidade de ser educada e libertada. Nesse sentido, podemos verificar que o sigilo que o orfismo guardava de seus rituais pode estar ligado ao fim último que era a salvação, não havendo necessidade de expor suas ações a não-iniciados. Os ensinamentos passados pelos praticantes não tinham o intuito de ser aberto ao público porque era pessoal e intransferível.

\section{Conclusão}

Como vimos, o mito juntamente com a poesia antiga foram as bases para as construções do pensamento dos primeiros filósofos, especialmente Empédocles. Para demonstrar isso, falamos do aedo em Empédocles e como o mesmo considerava-se poeta, sendo duas suas poesias que chegaram até nós. Ainda tratando sobre poesia e mito, foi mostrado a importância da poesia para o povo grego antigo e a semelhança e discordância da cosmologia de Hesíodo com a de Empédocles. Com o estudo feito da cosmogonia daquele, fizemos a comparação da cosmologia do pré-socrático com a dos órficos, introduzindo assim o leitor tanto na religião órfica quanto ao pensamento cosmológico de Empédocles.

Em seguida observamos mais de perto o pensamento de Empédocles sobre os quatros elementos 
primordiais e a regência dos mesmos pelo amor e ódio, assim como a relação dos tais elementos com o Esfero. Todo este conjunto de crenças e teorias encontra seu fio comum na concepção de daimon. Ela está subjacente na poesia hesiódica e sua concepção de Idade de Ouro, sendo esta a representação de uma era de felicidade perene entre homens e deuses. Por fim fechamos com a concepção órfica de do mesmo termo indicando como ela dialoga com preceitos do pensamento de Empédocles.

Verificamos que a obra do agrigentino está permeada de aspectos míticos, seja de origem hesiódica seja órfica. Em ambas as raízes, a radicalidade da questão cai sobre o destino último da alma humana. Esses aspectos ficam patentes tanto no dualismo corpo-alma como na cosmologia com fim salvacionista. $\mathrm{O}$ daimon é a alma, aquela que precisa ser purificada e protegida das ações do corpo para finalmente encontrar a libertação. Se nessa dualidade entre o corpo e a alma o corpo continuar controlando a alma, ela permanece no ciclo de encarnação sem conseguir libertar-se. Caso a alma siga as práticas corretas o corpo eventualmente morrerá e permitirá a transcendência imortal da alma. Este estudo teve como propósito investigar as relações sempre cambiantes entre mito e filosofia, além de perscrutar os canais de comunicação entre a poesia, religião e a filosofia.

A explicação da origem das coisas não nasceu com Empédocles. De fato, suas raízes se estendem até o umbral mítico que envolve o passado histórico da Hélade. Assim como outros povos em outros testemunhos deixaram registros de mitos de sucessão e/ou mitos de criação/ordenação, também os gregos associaram a dinâmica genealógica com o nascimento dos poderes cósmicos.

\section{Referências}

ALVARES, Jonatas Rafael. (2014). 0 papiro de Derveni e seus reflexos na filosofia antiga. Orientador Gabriele Cornelli. Dissertação (Mestrado em Filosofia). Universidade de Brasília, Brasília, $121 \mathrm{f}$.

ARISTÓTELES. (IV a.C.) Metafísica. 3 vol. Introdução, tradução e comentário de Giovanni Reale. São Paulo: Loyola, 2001.

BERNABÉ, Alberto. (2008). Fragmentos pré-socráticos de Tales a Demócrito. Madrid: Alianza. BRUN, Jean. (1968). Os pré-socráticos. Trad. Armindo Rodrigues. Rio de Janeiro: Edições 70, 1991.

COSTA, Alexandre. (2012). Mito e Filosofia em Empédocles. In: Anais de Filosofia Clássica, Rio de Janeiro: Universidade Federal do Rio de janeiro- UFRJ, vol. VI, nº11.

. (2002). Como e por que sobrevivem os pré-socráticos? In: Revista Filosófica de Coimbra. Coimbra: Universidade de Coimbra, v. 11, n. 21, p. 163-178, março.

HESÍODO. (VIII a.C.).Teogonia: A Origem dos Deuses. $3^{\circ}$ ed. Tradução e estudo Jaa Torrano. São Paulo: Iluminuras LTDA, 1995.

2012.

Os Trabalhos e Os Dias. $22^{\circ}$ ed. Trad. Alessandro Rolim de Moura. Curitiba, PR: Segesta,

OLIVEIRA, Anselmo Carvalho de. (2004). Orfismo, uma nova dimensão do homem grego. In: Ágora Filosófica: Revista Semestral do Departamento de Filosofia - Unicap, Recife: FASA Editora, ano 4, v. 2, n. 2, p. 7 - 19, jul. - dez.

OS PRÉ-SOCRÁTICOS: Vida e obra. Fragmentos, doxografia e comentários de José Cavalcante de Souza. São Paulo: Nova Cultural, 1996. (COLEÇÃO OS PENSADORES). 
PEREIRA, Ivanete. (2006). Aspectos sagrados do mito e do lógos: poesia hesiódica e filosofia de Empédocles. São Paulo: Educ.

- (2003). Considerações sobre Empédocles e a ordem órfico-pitagórica. In: Hypnos, São Paulo: ano $8 / \mathrm{n}^{\circ} 11-2^{\circ}$ sem. p. 98-111.

TORRANO, Jaa. (1995). Estudo Introdutório. In: Teogonia: A Origem dos Deuses. $3^{\circ}$ ed. São Paulo: Iluminuras LTDA, p. 8 - 86.

VERNANT, Jean Pierre. Mito e religião na Grécia antiga. Trad. Joana Angélica d' Ávila Melo. São Paulo: Martins Fontes, 2006.

Artigo recebido em: 12 de janeiro de 2020

Artigo aceito em: 21 de fevereiro de 2020 